WSRC-MS- -90-94

INDUSTRIAL POWER DISTRIBUTION (U) DE91 000785

by

Mark A. Sorrells

Westinghouse Savannah River Company

OLT 151990

Savannah River Laboratory

Aiken, SC 29808

An article proposed for presentation

Seminar - Industrial Power Distribution

Cookeville, TN

April 24, 1990

\title{
DISCLAIMER
}

\begin{abstract}
This report was prepared as an account of work sponsored by an agency of the United States Government. Neither the United States Gnvernment nor any agency thcreof, nor any of their employees, makes any warranty, express or implied, or assumes any legal liability or responsibility for the accuracy, completeness, or usefulness of any information, apparatus, product, or process uisclosed, or represents that its use would not infringe privately owned rights. Reference herein to any specific commercial product, process, or service by trade name, trademark, manufacturer, or otherwise does not necessarily constitute or imply its endorsement, recommendation, or favoring by the United States Government or any agency thereof. The views aist opinions of authors expressed herein do not necessarily state or reflect those of the Uniteci States Government or any agency thereof.
\end{abstract}

This article was prepared in connection with work done under Contract No. DE-AC09-88SR 18035 with the U.S. Department of Energy. By acceptance of this article, the publisher and/or recipient acknowledges the U.S. Government's right to retain a nonexclusive, royalty-free license in and to any copyright covering this article, along with the right to reproduce and to authorize others 0 reproduce all or part of the copyrighted article. 


\title{
Industrial Power Distribution(U)
}

\author{
Mark A. Sorrells
}

I. Single Line

II. Primary Power Distribution

ill. Secondary Distribution
A. Transiormers
B. Secondary Switchgear
C. Motor Control Centers
D. Distribution Panels

IV. Utilization Equipment
A. Motors
B. Lighting Loads

V. Protection Devices
A. Circuit Breakers
B. Fuses
C. Relays

VI. Standards
A. NFPA 70 - National Electrical Code
B. ANSI C2 - National Electrical Safety Code
C. IEEE Color Series
D. National Electrical Manufacturer's Association

VII. Case Studies
A. Installation of $75 \mathrm{HP}$ Motor
B. Installation of 45 KVA Lighting Transformer 


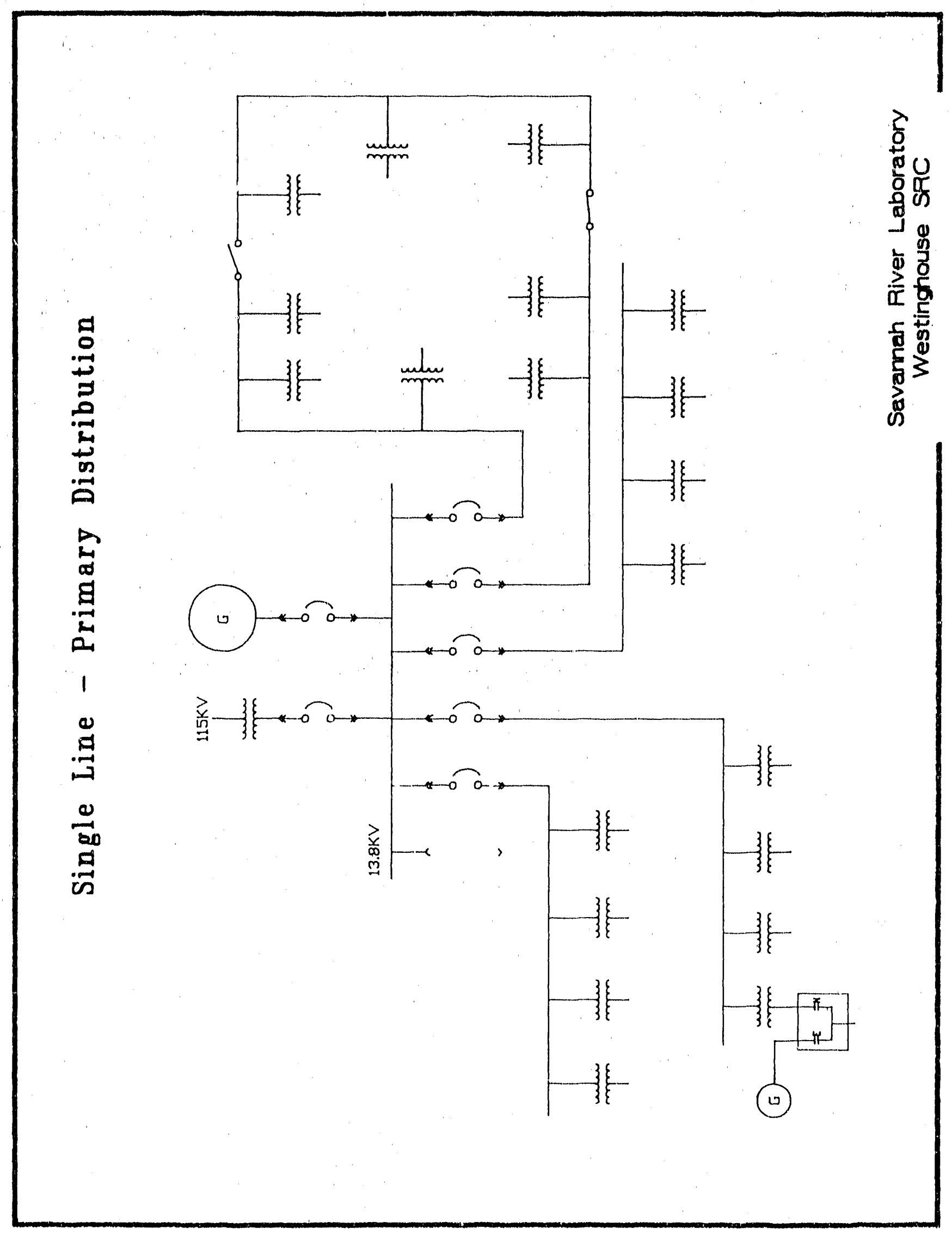




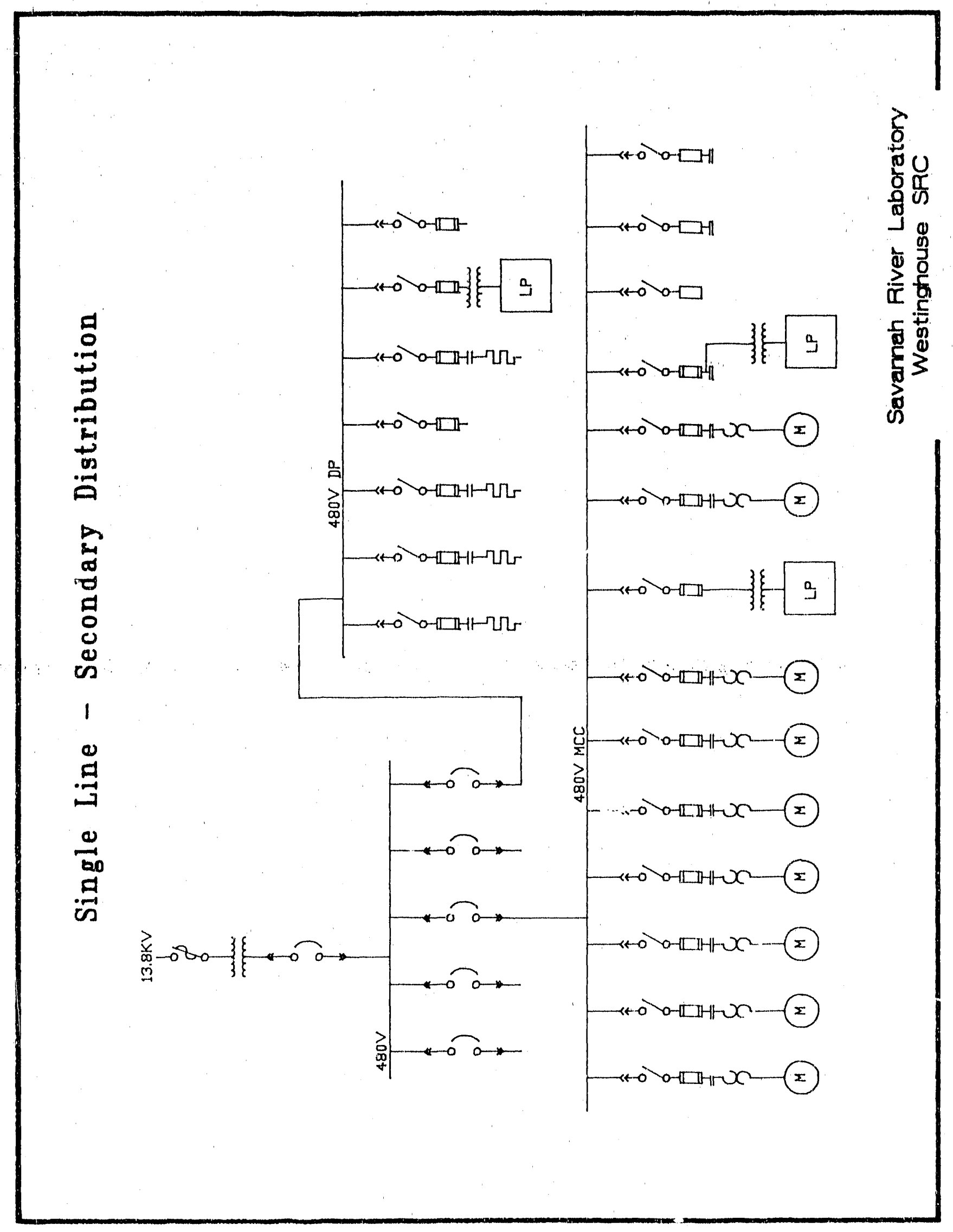




\section{Utilization Equipment}

480V Most Prevalent in SouthEast

Motors

$1 / 2$ - 150h-1P (Induction)

DC for Precision Control

Lighting Loads

480 - 240/120 Single Phase

480 - 208/120 Three Phase

480 - 240/120 Three Phase (Hi Leg Delta) 


\section{Protection Devices}

Circuit Breakers

Reset Capability

Limited SC Capacity

Fuses

One Time Devices

High SC Capacity

Relays

Motor Overloads

Ground Fault Detectors

Undervoltage Relays 


\section{Standards}

NFPA 70 - National Electrical Code

ANSI C2 - National Electrical Safety Code

IEEE Color Series

Green Book - Grounding

Buff Book - Protection \& Coordination

Brown Book - Power System Analysis

National Electrical Manufacturer's Association 


\section{Motor Circuit Considerations}

Horsepower

$$
\begin{aligned}
& <1 / 2 \mathrm{HP} \\
& 1 / 2 \mathrm{HP} \text { to } 150 \mathrm{HP} \\
& >150 \mathrm{HP}
\end{aligned}
$$

Voltage Available

120, 208, 240 Single Phase

208 or 460 Three Phase

NEMA MG-1 \& MG-2

Starting Torque

Orientation of Motor

Orientation of Terminal Box 


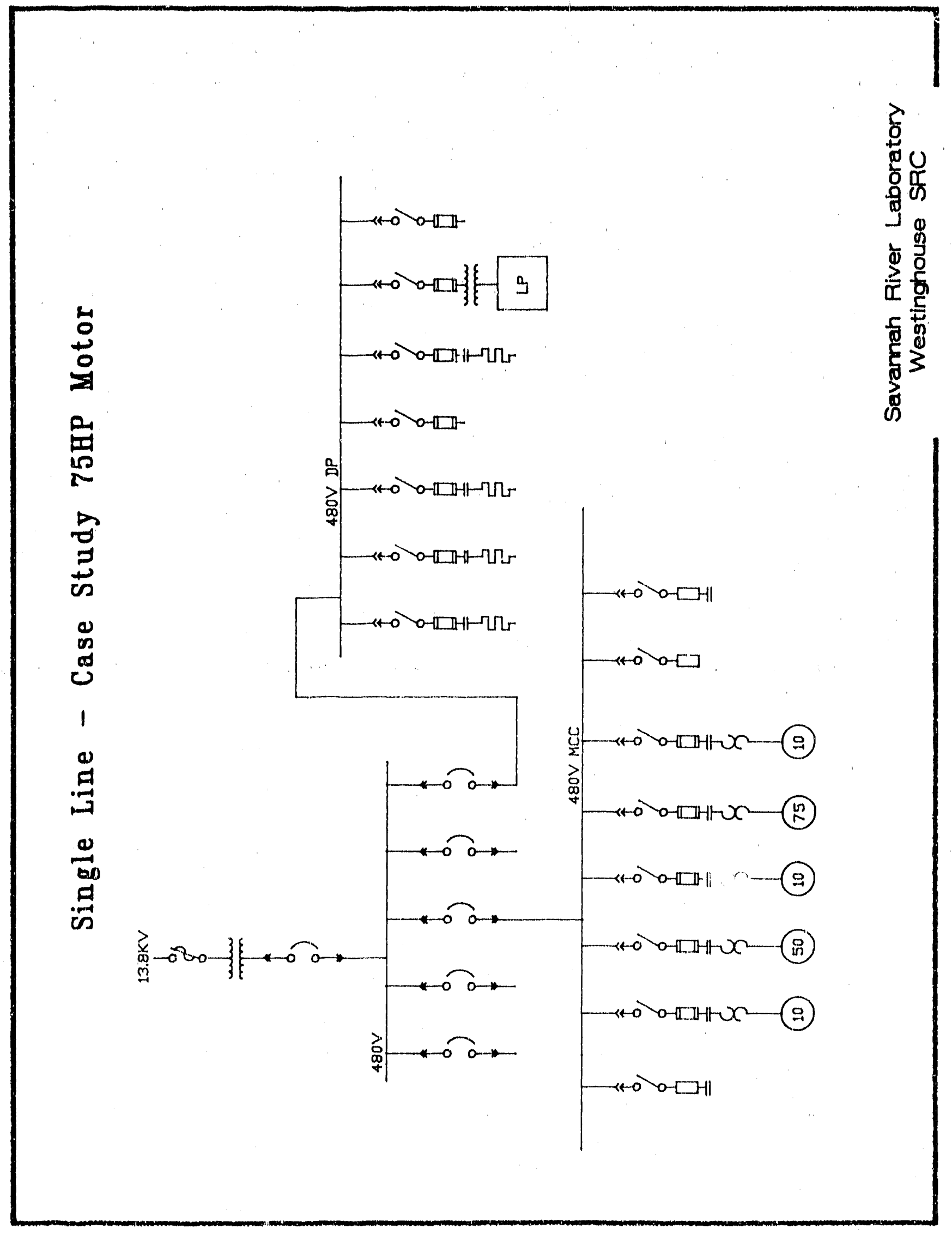




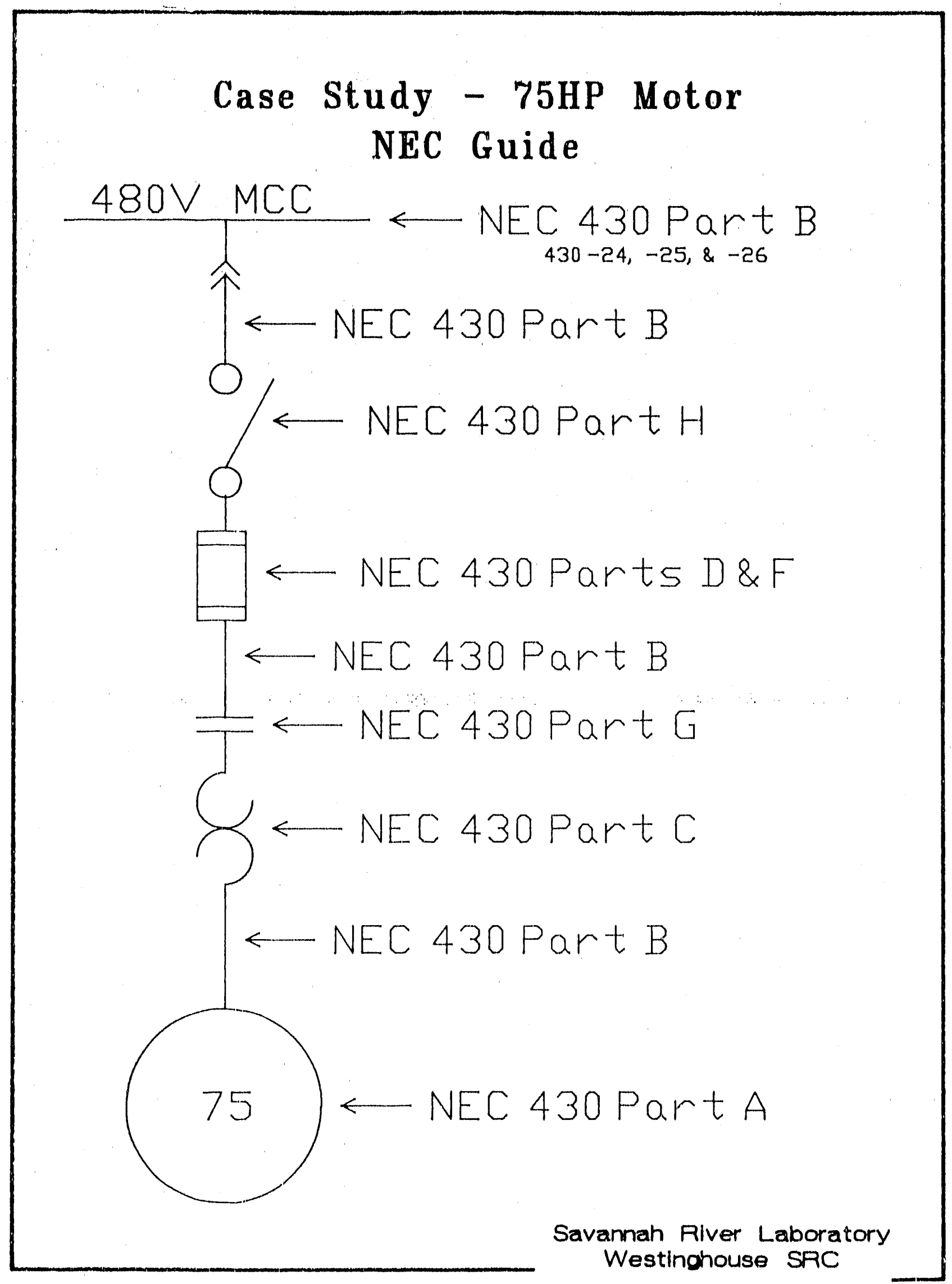


Case Study - 75HP Motor Computed Values

480V MCC

NEC $430-24(a)$

$\longleftarrow \quad \begin{aligned} & 310 \mathrm{HP}, 150 \mathrm{HP}, 1775 \mathrm{HP} \\ & 3 \times 14+1 \times 65+1.25 \times 96\end{aligned}$

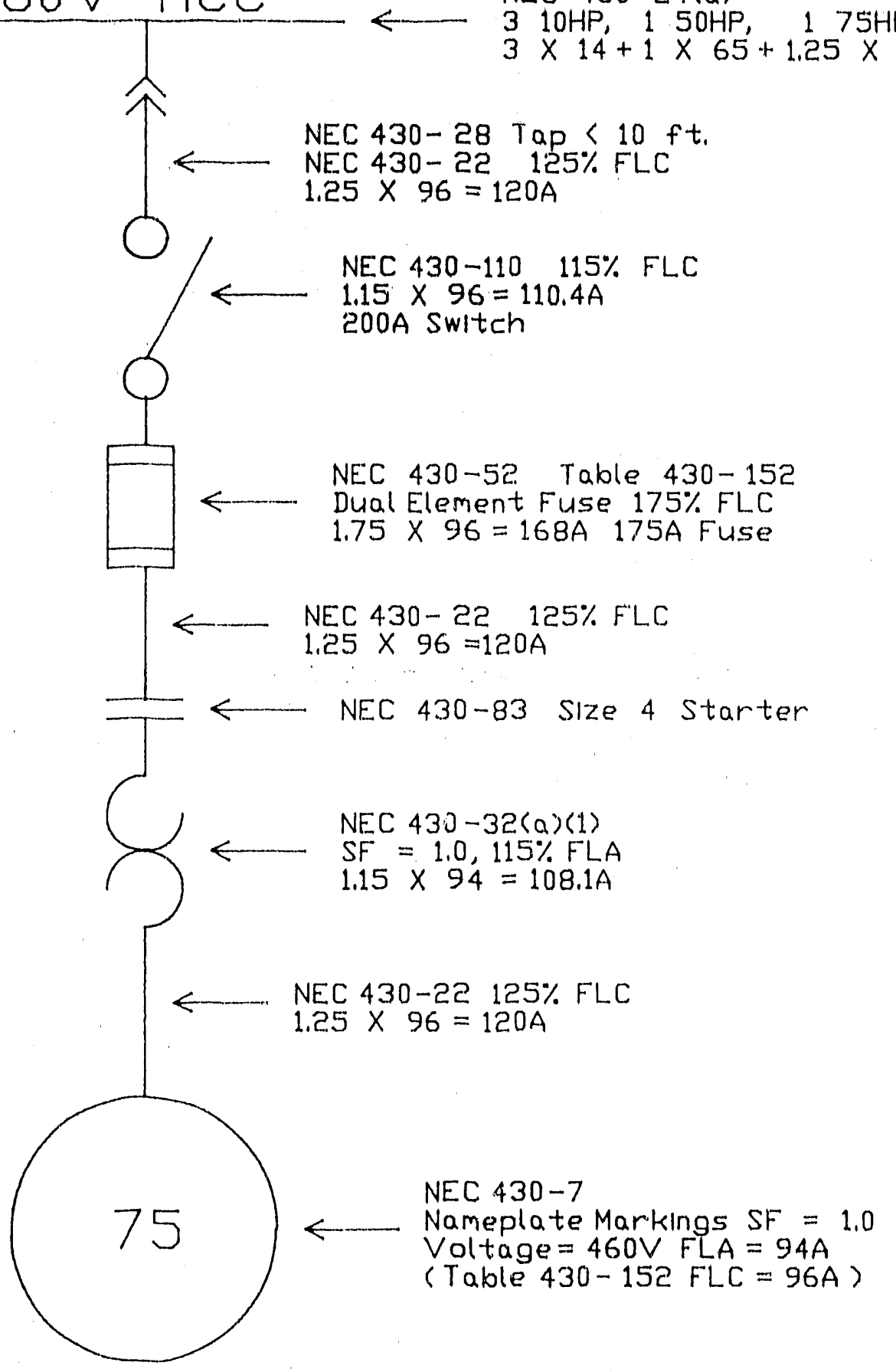

Savarnah River Laboratory Westinghouse SRC 


\section{Lighting Considerations}

Common Voltage At Site 240/120 Single Phase 208/120 Three Phase

Common Transformer Sizes

Location of Transformer Inside or Outside

Corrosive Atmosphere Heat Dissipation 


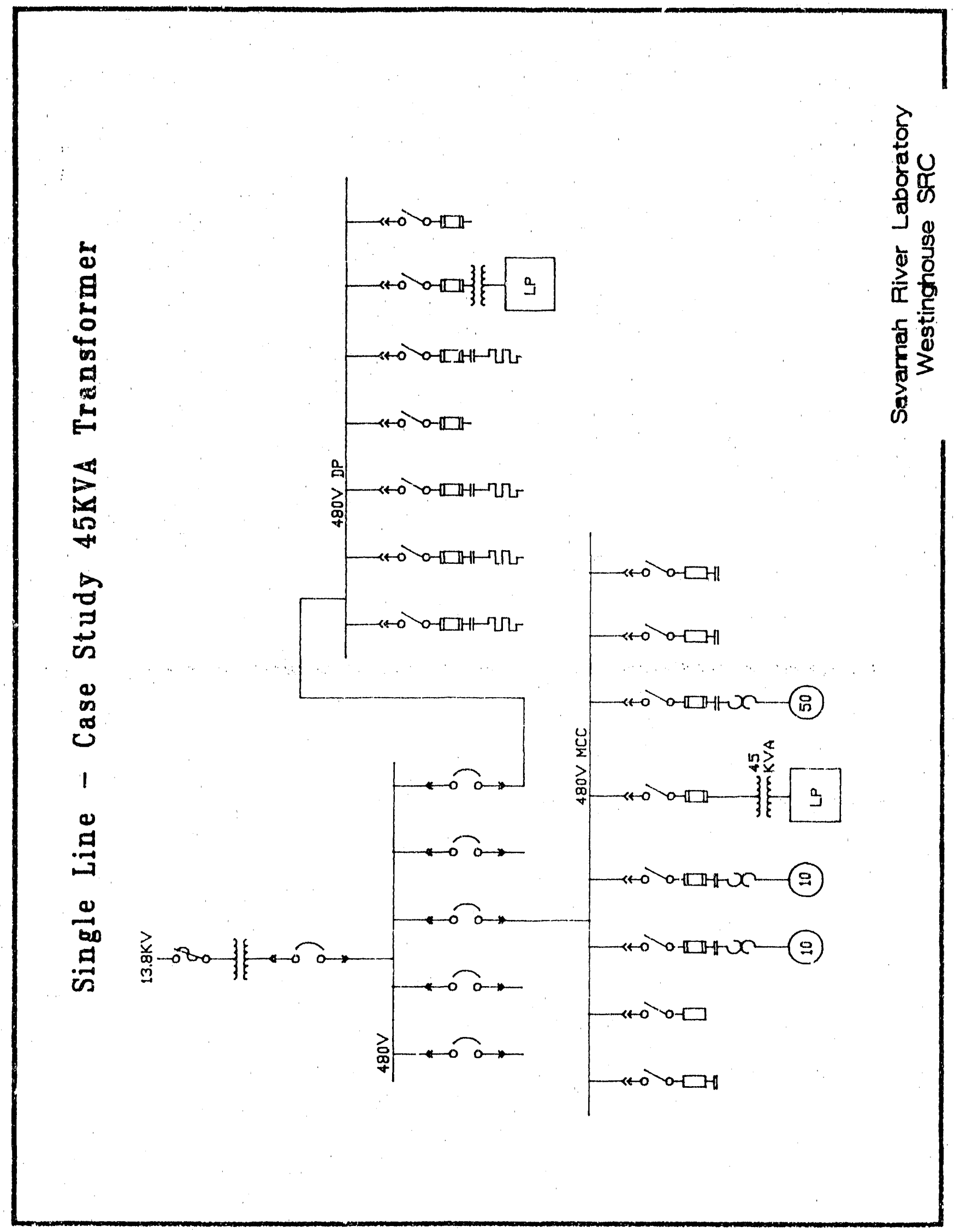




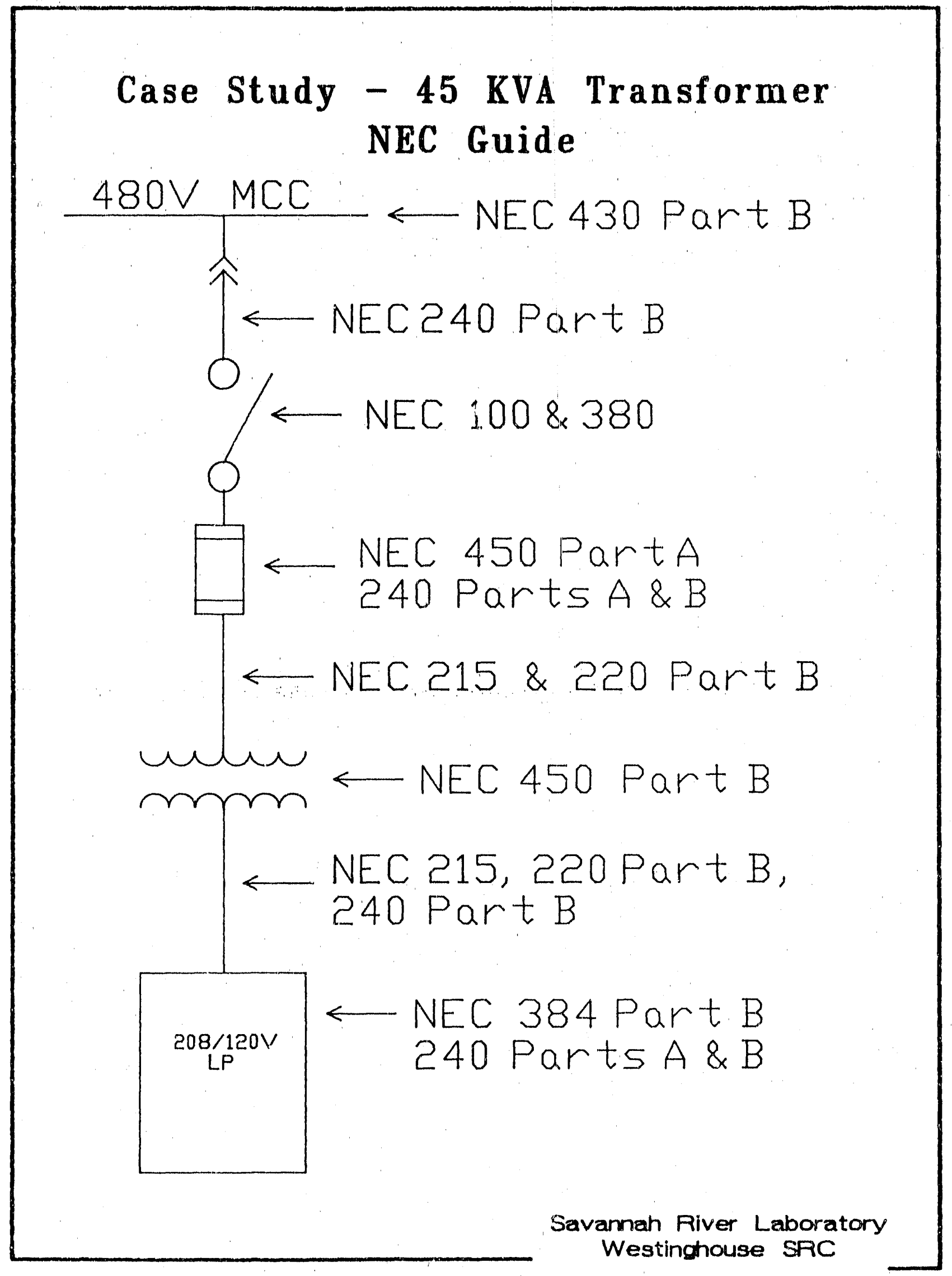




\section{Case Study - 45 KVA Transformer Computed Values}
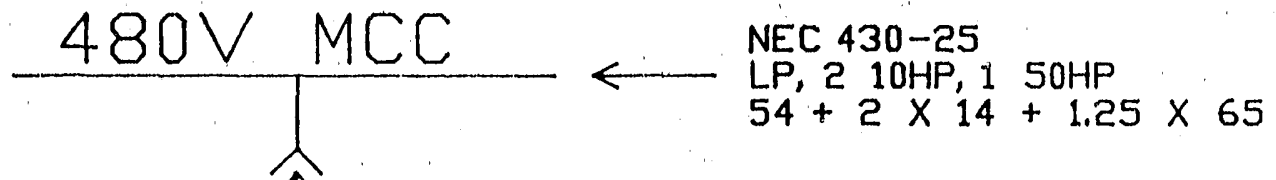

LP, 2 10HP, $150 \mathrm{HP}$

$$
\text { (NEC 240-21 }
$$




\section{Industrial Power Distribution (U)}

Mark A. Sorrel1s

Westinghouuse Savannah River Company

\section{(Introductory slide)}

This talk will be a broad overview of industrial power distribution. Primary focus will be on selection of the various Low voltage components to achieve the end product. Emphasis will be on the use of national standards to ensure a safe and well designed installation. (Read over outline.)

\section{(Single Line Primary Distribution Slide)}

The single line diagram is one of the most important, if not the most important, drawing the electrical power engineer uses. It shows how power is distributed to all electrical machinery in the plant.

Primary power is usually supplied at some medium voltage level $(13.8 \mathrm{KV}$ to $69 \mathrm{KV})$. Occasionally the power company will supply this voltage through a step-down transformer from some transmission level voltage such as $115 \mathrm{KV}$. Distribution is then made at the selected medium level voltage. Onsite generation is a distinct possibility at many facilities. 5 MW to 30 MW is a typical range. For the onsite cogenerator.

The medium voltage distribution may be done via overhead lines, underground lines, cable tray, or some combination of these methods. Distribution feeders nay be in ci loop, radial, or primary selective arrangement. 


\section{(Single Line Secondary Distribution Slide)}

Transformers are used to step the medium voltage down to the final utilization voltage. This utilization voltage will depend primarily on the size of the equipment.

These transformers will usually range in size from 500 KVA to 2500 KVA. A number of factors affect this selection. What will be the load demand? Is there a possibility of future expansion? What size transformers are available within the necessary time frame? Is there a desire to have standard sizes in order to reduce replacement inventory?

Transformers come in two basic types - liquid immersed and dry-type. With liquid inmersed types, the winding and core are totally submerged in a liquid that serves as a heat-transfer medium and as an is sulating dielectric. With a dry type, the core and winding assembly operate in a gas (usually air). Each type has its advantages and disadvantages.

Transformers may be a part of a unit substation or separate from the secondary switchgear. Switch distribution is usually made through busbar to feeder breakers, which go in turn to additional. secondary distributi'n gear.

One of the more common methods for final low voltage distribution is a motor control center. Motor control centers (MCC's) consist of stacks with vertical busbars from which the power is supplied. Cubicles have stabs which plug onto these busbars. The necessary motor control components are included in this bucket or can. MCC's are a very convenient method of: 
locating control for many motors in one centralized area.

Another method for low voltage distribution is a panelboard. These may use fuses or circuit breakers. They are similiar to your household li.ghting panel. They are used when the loads to be fed require only a power input, such as packaged HVAC units and transformers.

\section{(Utilization Equipment Slide)}

Motors are a large part of any industrial facility's load. By far the largest portion of motors in use in the United States are squirrel cage induction motors. They are simple, relatively maintenance free, and a proven technology. DC motors are used when a high degree of speed and/or motion control is desired.

Task lighting is an important part of getting the job done. Common practice is to utilize the main low voltage distribution to feed lighting transformers. The final lighting voltage is usually determined by company practice, and/or the anticipated equipment to be served.

(Protection Devices Slide)

There are two main types of short circuit protective devices available, fuses and circuit breakers. Each has its advantages and disadvantages. They each come in a variety of styles. Fuses come in various UL classes, with the main factors being size and interrupting capacity. Circuit breakers may be molded case, ACB, have interchangeable plug trips, and other assorted add-on functions. 
While short circuits may be spectacular, they are not the only type of system disturbance. Many start out as an aroing ground fault. This type of fault is characterized by a high impendance to ground, often undetectable by the short circuit protective device.

Relays are available to detect ground faults, as well as a variety of other lypes of faults. These include undervoltage relays and thermal overloads.

\section{(Standards Slide)}

A large quantity of standards exist in the United States, and worldwide. These are most often driven by the need to, as the name suggests, standardize on a method of doing something, dimensions of certain products, or some other common thread.

The most important document the electrical power engineer. uses is the National Electrical Code. It is not the only standard one needs to be aware of. There are others, such as the National Electrical Safety Code, the IEEE color series, and the National Electrioal Manufacturer's Association (NEMA) standards.

\section{(Motor Circuil Considerations Slide)}

The first two factors usually considered in designing a motor hookup are 1) horsepower, and 2) the available voltage. Many companies have defiined breakpoints at which they change the voltage and phase of the motor. For example, one possible breakdown would be $120 \mathrm{~V}$ single phase for less than $1 / 2 \mathrm{HP}, 460 \mathrm{~V} 3$ 
phese for $1 / 2 \mathrm{HP}$ up to $150 \mathrm{HP}$, and $2300 \mathrm{~V}$ for motors larger than $150 \mathrm{HP}$. On occasion, one may need to adjust the voltage of the notor due to the nonavailability of the usually preferred voltage. For example, a $200 \mathrm{HP}$ motor may be required in a certain situation, but only $480 \mathrm{~V}$ is readily available.

Sometimes other considerations come into play. NEMA MG-1, Mr.tors and Generators, and NEMA MG-2, Safety Standard for Construction and Guide for Seloction, Irstallation, and use of Electric Motors, can sometimes help in these situations.

\section{(75HP Motor Single Line Slide)}

outlined in red is the power flow for consideration. Let us consider adding a $75 \mathrm{HP}$ to a $480 \mathrm{~V}$ motor control center. Let us also assume there will be three $10 \mathrm{HP}$ motors and one $50 \mathrm{HP}$ motor on this motor control. center.

\section{(75HP Motor NEC Guide Slide)}

Here is the single line for the motor circuit, along with the various governing sections from NEC article 430 .

\section{(75HP Motor Computed Values Slide)}

We know the horsepower and voltage. We take several paths to arxive at our final product.

Per NEC 430-24(a) our bus must be able to handle the FLC (full load current) of all other motors plus $125 \%$ of the largest motor. Doing our calculation, we get 227A. Vertical bus is 
usally rated at $300 \mathrm{~A}$, and horizonal busbar is usally 600 or $800 \mathrm{~A}$. Moving to our stab connection, per NEC 430-28, we have a tap less than 10 feet so our conductors may be sized for the branch circuit. NEC 430-22 defines the conductor size at $125 \%$ of the FLC for $120 \mathrm{~A}$.

The switch must be sized at $115 \%$ of the motor FLC. This figure is 110.4A. Switches dome in standard sizes, 30, 60, 100, 200, etc. We will need a 200A switah.

To size the overcurrent device, we use Table 430-152. If we have a dual element fuse, it should be sized at $175 \%$ FLC. Fuses also come in standard sizes. Recognizing this, we can use an exception to go to the next higher standard size fuse, which is $175 \mathrm{~A}$.

Again, the feeder to the contactor must be sized for $125 \%$ FLC. Per NEC 430-83, the horsepower rating of the controller. must greatex than or equal. to the nameplate horsepower of the motor.

Overloads are sized based on the actual motor nameplate data. Let us assume our Full load Amps (FLA) equals 94A. Per. NEC 430-32(a)(1) we size the overload for 108.1A. Motor overloads are selected from a manufacturer's chart.

The branch circuit again must be sized for $125 \%$ FLC. Per NEC 430-7, motors must carry a nameplate with various markings, some of which we used to dalculate above values. 


\section{(Lighting Considerations Slide)}

Some Eactors to consider in designing a lighting layout include the site's common voltage, the desire to standardize for inventory reduction, and the looation of the transformer.

\section{(45KVA Transformer Single Line Slide)}

Outlined in red is the power flow for consideration. Let us consider adding a lighting transformer to a motor control denter. Our lighting voltage will be $208 / 120 \mathrm{~V}$ three phase. Let us also assume there will be two $10 \mathrm{HP}$ motors and one $50 \mathrm{HP}$ motor on this motor control center.

\section{(45KVA Transformer NEC Guide Slide)}

Here is the single line for the transformer and lighting panel, along with the governing sections from various NEC articles.

\section{(45KVA Transformer Computed Values Slide)}

Our first oonsideration is to determine the KVA load we will have. Computing the load pex NEC 220, we must take $1.00 \%$ of the lightirg load, $100 \%$ of the first 10 KVA receptacle load, and $50 \%$ of the remaining redeptacle load. With a lighting load of $12 \mathrm{KVA}$ and a receptacle load of 1.4 KVA, our computed load will total 24 KVA.

Some common three phase transformer sizes are 30,45 , and 75 
KVA. With today's explosion in the computer areria, the receptacle load could quidkly increase. Thersfore it would be prudent to install a 45 KVA transformex, even though a $30 \mathrm{KVA}$ would be adequate at present.

Since we are connecting to a MCC, our busbar must me日t $430-$ 25. We must size for all other motors, $125 \%$ f the largest motor, and other computed loads. 45 KVA works out to $54 \mathrm{~A}$ on the $480 \mathrm{~V}$ supply side. Doing our calculation, the busbar must be capable of handling $163 \mathrm{~A}$.

NEC 240-21 limits our tap conductor to the switch to less than 10 feot in length. Our switch is a knife type and is classified as a general-use switoh per NEC 380-13. NEC 1.00 defines a general use switch as being rated in amperes, and capable of interrupting its rated current at its rated voltage. Therefore our switch must handle $54 \mathrm{~A}$.

Sizing the fuse per NEC $450-3(b)(1)$, the primary overcurrent device may be sized up to $125 \%$ of the primary current. This overcurrent device must be placed where the conductor receives its supply, in the MCC. We will use a $70 \mathrm{~A}$ fuse. This means that. our switch will need to be a $100 \mathrm{~A}$ switah, even though a $60 \mathrm{~A}$ switch would meet the necessary oriteria.

per 215-2, the transformer supply conductors must be protected at their ampacity from Tables 310-16 to 310-19. Section 220-10 states that the conduotors must handle the computed load. Since we selected the fuse at $125 \%$, the conductors must carry this current in order to be properly 
protected. We will ohoose \#4 AWG cunductors.

The transformer will be of the dry-type, and must be installed in accordance with NEC 450-21. This artiole states that the transformer must be installed 12 inches from any combustible material. Once the transformer size gets over $1121 / 2$ KVA, they must be installed in a special fire resistant room.

The conductors to the lighting panel will be less than 10 feet, so they will not require an overcurcent protection device. They must be sized to carry the computed load. Since we have chosen to use a 45 KVA transformer, we should use this rating to calculate the wire size and the panelboard size.

Per NEC 384-16, this panelboard must be protected on the supply side by an overcurrent device. In addition, it may not carry more than $80 \%$ of its rating where the loads are continuous. The exception to this rule states that all the devices must be rated for $100 \%$ duty. The full capacity of the transformer is 124.9A. We will therefore use a $125 \mathrm{~A}$ panelboard.

\section{ACKNOWLEDGMENT}

The information contained in this article was developed durtng the course of work done under Contract No. DE-ACO988 SR18035 with the U. S. Department of Energy. 

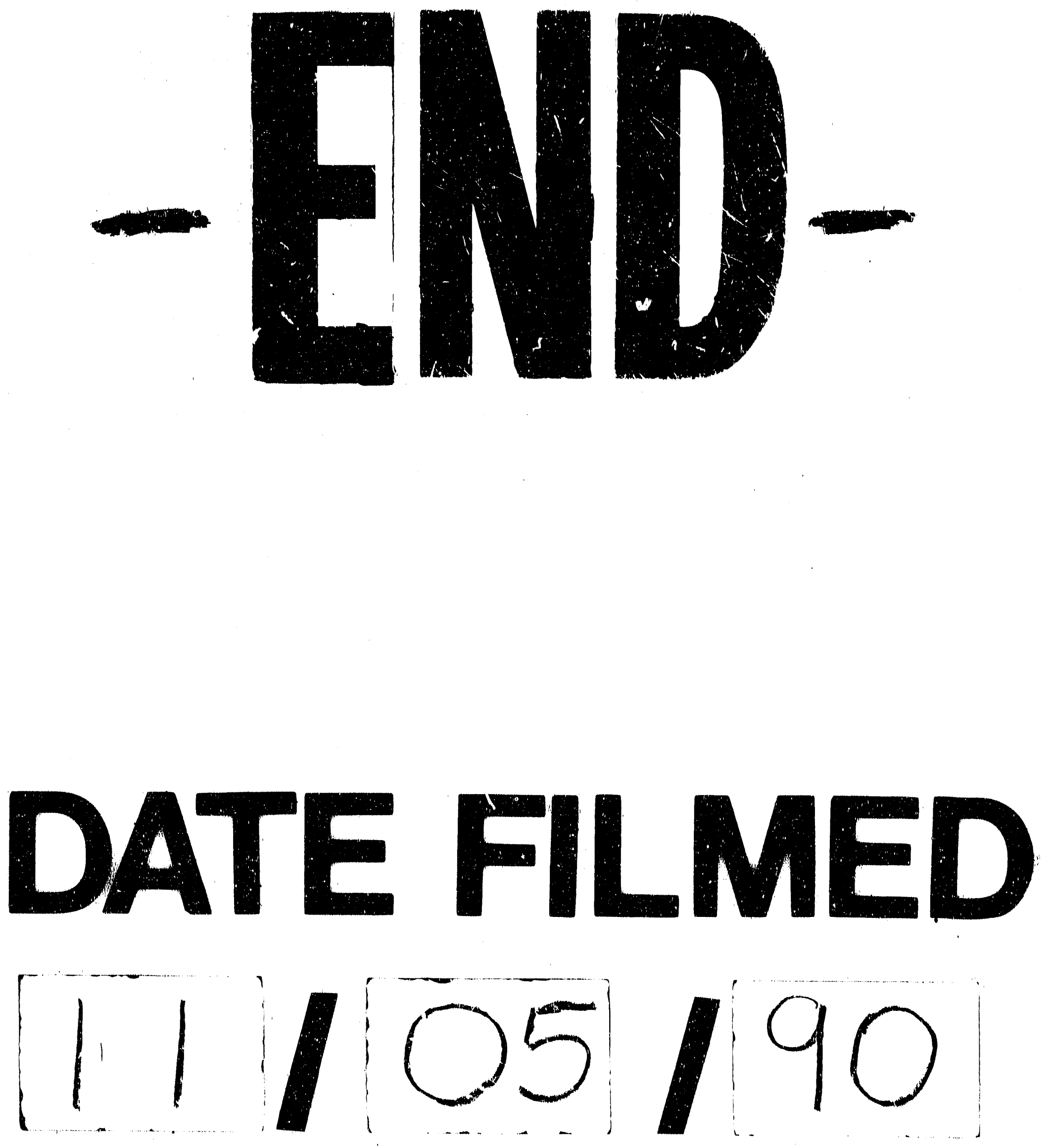
$\mid$

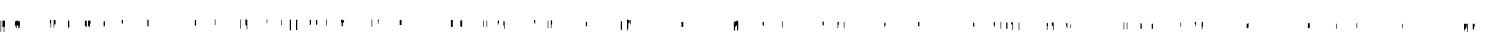

